\title{
Invaziv Duktal Meme Karsinomu Tedavisi Sonrası Gelişen Akut Myeloid Lösemi
}

\author{
Acute Myeloid Leukemia After the Treatment of \\ Invasive Ductal Breast Carcinoma
}

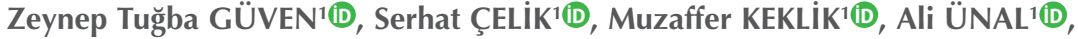 \\ Leylagül KAYNAR ${ }^{2} \mathbb{D}$ \\ ${ }^{1}$ Erciyes Üniversitesi Tıp Fakültesi, Hematoloji Bilim Dalı, Kayseri, Türkiye \\ ${ }^{2}$ Medipol Üniversitesi Tıp Fakültesi, Hematoloji Bilim Dalı, İstanbul, Türkiye
}

\section{öz}

Amaç: Bu retrospektif çalışmada geçmişte meme kanseri tedavisi alan ve akut myeloid lösemi gelişen hastaların sonuçlarına dair tek merkez deneyimimizi paylaştık.

Hastalar ve Yöntem: Çalışmaya 2013-2020 yılları arasında Erciyes Üniversitesi Hematoloji bölümünde takip edilen 10 kadın akut myeloid lösemi (AML) hastası dahil edildi.

Bulgular: Hastaların tamamı geçmişte invaziv duktal karsinom tanısı almış idi. Sekiz (\%80) hasta kemoradyoterapi alırken, 2 hasta sadece kemoterapi almıştı. Kemoterapi olarak tüm hastalara antrasiklin bazıı tedaviler uygulanmıştı. Meme kanseri tanısı ile akut lösemi tanısı arasında geçen süre median 52 ay (7-110) idi. Indüksiyon tedavisi olarak 7 (\%70) hasta idarubisin ve sitarabin alırken, 1 hasta azasitidin aldı. İlk indüksiyon sonrası hastaların yarısında tam remisyon sağlandı. Dört (\%40) hastaya tam uyumlu kardeş vericiden allojenik nakil yapıldı. Sekiz (\%80) hasta hayatını kaybetti. En sık ölüm nedeni hastalık nüksü idi. İki hasta ise halen remisyonda takip edilmektedir. Akut lösemiden sonra ortanca takip süresi 14 ay (0.9-86 ay) idi.

Sonuç: Tedavi ilişkili akut myeloid lösemi (t-AML) meme kanserini tedavisi sonrası korkulan bir sonuçtur. Meme kanserinin erken evrede saptanması, hastaların yoğun kemoterapi ve radyoterapiye maruziyetini azaltacağından t-AML riskini de azaltacaktır. Meme kanseri tedavisi gören her hasta t-AML açısından yakından ve dikkatle izlenmelidir.

Anahtar Kelimeler: Meme kanseri; İnvaziv duktal karsinom; Akut myeloid lösemi; t-AML

\section{ABSTRACT}

Objective: In this retrospective study, we shared our single-center experience of the outcomes of patients who had previously received breast cancer treatment and developed acute myeloid leukemia.

Patients and Methods: Ten female acute myeloid leukemia (AML) patients followed in the Hematology Department of Erciyes University between 2013 and 2020 were included in the study.

Results: All of the patients had been diagnosed with invasive ductal carcinoma in the past. Eight (80\%) patients received chemoradiotherapy, while two patients received only chemotherapy. Anthracycline-based treatments were administered to all patients as chemotherapy. The median time between the diagnosis of breast cancer and the diagnosis of acute leukemia was 52 months (7-110). As induction therapy, 7 (70\%) patients received idarubicin and cytarabine, and 1 patient received azacitidine. Complete remission was achieved in half of the patients after the first induction. Four (40\%) patients underwent allogeneic transplantation from a fully matched sibling donor. Eight $(80 \%)$ patients died. The most common cause of death was disease recurrence. Two patients are still being followed in remission. The median follow-up time after acute leukemia was 14 months (0.9-86 months).

Makale atıfı: Güven ZT, Celik S, Keklik M, Ünal A, Kaynar L. İnvaziv duktal meme karsinomu tedavisi sonrası gelișen akut myeloid lösemi. LLM Dergi 2021;5(3):669.

\section{Yazıșma Adresi}

\section{Zeynep Tuğba GÜVEN}

Erciyes Üniversitesi Tıp Fakültesi, Hematoloji Bilim Dalı,

Kayseri-Türkiye

Geliş: 07.12.2021 - Kabul: 13.01.2022

E-posta: drztkarabulutguven@gmail.com 
Conclusion: Treatment related AML is a feared outcome after breast cancer treatment. Detection of breast cancer at an early stage will reduce the risk of $\mathrm{t}-\mathrm{AML}$ as it will reduce the exposure of patients to intensive chemotherapy and radiotherapy. Every patient treated for breast cancer should be followed closely and carefully for t-AML.

Key Words: Breast cancer; Invasive ductal carcinoma; Acute myeloid leukemia; t-AML

\section{GíRiş}

Meme kanseri kadınlarda en sık görülen kanserdir ve kanser ilişkili ölümlerin önemli bir nedenidir (1). Histolojik olarak meme kanserinin en sık görülen formu invaziv duktal karsinomdur (2). Görüntüleme yöntemleri ve tedavi seçeneklerindeki gelişmeler sayesinde sağkalım önemli ölçüde iyileşmiştir. Ancak antrasiklinler, alkilleyici ajanlar ve radyoterapi kullanımı ile tedaviye bağlı yan etkiler kaçınılmaz olarak artmıştır (3). Birçok çalışmada meme kanseri tedavisi sonrası diğer malignitelerde artış olabileceği vurgulanmıştır $(4,5)$. Bunlardan biri de tedaviye bağlı akut miyeloid lösemidir (t-AML). Meme kanseri tedavisinden sonra ikincil akut lösemi riski beş yıldan sonra belirgin olarak artar (6).Bu durum meme kanserinde sağkalımı arttıran ve tedavinin en önemli elemanı olan alkilleyici ajanlar ve topoizomeraz 2 inhibitörleri ile ilişkilendirilmiştir. Tedaviyle ilişkili akut miyeloid lösemi 2016 Dünya Sağlık Örgütü sınıflandırmasında "Akut miyeloid lösemiler ve ilgili neoplazmalar" arasında yer alır (7). Illk tanı ile tedaviyle ilişkili hastalık arasındaki zaman, önceki sitotoksik tedavinin toplam dozuna, doz yoğunluğuna ve ayrıca tedavi süresine bağlı olarak, medyan iki yıl civarındadır $(8,9)$.

De novo AML'ye göre t-AML'li hastalar, daha kötü sitogenetik özelliklere ve daha kısa sağkalım sürelerine sahiptir $(10,11)$. Ayrıca bu hastalar akut lösemide kullanılan geleneksel tedavilere, de novo lösemiye göre daha dirençlidir. Kemoterapinin yanı sıra radyasyon tedavisinin ve granülosit koloni uyarıcı büyüme faktörlerinin de $\mathrm{AML}$ riskin- de artışa neden olabileceği bildirilmiştir $(12,13)$. Bu yazıda ailesinde hematolojik malignite öyküsü olmayan, daha önce meme kanseri tedavisi görmüş ve akut miyeloid lösemi tanısı alan hastaların klinik ve demografik özelliklerini değerlendirmeyi ve literatüre katkı sağlamayı amaçladık.

\section{HASTALAR ve YÖNTEM}

Bu çalışmaya Temmuz 2013-Temmuz 2020 tarihleri arasında Erciyes Üniversitesi Tıp Fakültesi Hematoloji Kliniği'nde AML tanısı almış, geçmişte meme kanseri tedavisi alan 10 kadın hasta dahil edildi. Çalışma için Erciyes Üniversitesi Tıp Fakültesi Etik Kurulu'ndan 22/09/2021 tarih ve 2021/611 karar numarası ile etik kurul onayı alındı. Çalışmada kullanılan tüm veriler elektronik dosyalardan geriye dönük olarak toplandı. Çalışmaya dahil edilen tüm olgular 18 yaş üzeri idi ve 2016 yılı DSÖ kriterlerine göre AML tanıSı alan olgulardır. Tüm olgular geçmişte patolojik inceleme sonucu invaziv duktal meme karsinomu tanısı almış ve tedavi görmüşlerdir.

Veriler SPSS versiyon 21.0 ile işlenmiştir. Sayısal değişkenler ortanca, ortalama ve dağılım olarak belirtilmiştir.

\section{BULGULAR}

Çalışmaya alınan 10 kadın AML hastasının ortanca yaşı 55 (50-78) idi. Hastaların tamamı geçmişte patolojik olarak invaziv duktal karsinom tanısı almış idi. Hastaların klinik özellikleri Tablo 1'de belirtilmiştir. Hastaların tamamına meme kanseri nedeniyle mastektomi uygulanmıştı.

Tablo 1. Hastaların klinik özellikleri

\begin{tabular}{lccccccc} 
Hasta no & Yaş/Cinsiyet & $\begin{array}{c}\text { Meme kanseri } \\
\text { tedavisi }\end{array}$ & RT & $\begin{array}{c}\text { Genetik } \\
\text { özellik }\end{array}$ & AML tedavisi & AHKHN & Sağkalım \\
\hline 1 & $55 /$ Kadın & AC+PTx & Var & Yapılmadı & Azasitidin & - & Ölüm \\
2 & $50 /$ Kadın & AC+PTx & Var & Flt-3 & $3+7$ ve FLAG & Var & Ölüm \\
3 & $58 /$ Kadın & AC+PTx & Var & Yapılmadı & - & - & Ölüm \\
4 & $52 /$ Kadın & AC+PTx & Var & t(8;21) & $3+7$ ve FLAG & Var & Sağ \\
5 & $59 /$ Kadın & AC+PTx & Var & Trizomi 8 & $3+7$ ve FLAG & Var & Ölüm \\
6 & 78/ Kadın & AC & Yok & Yapılmadı & - & Ölüm \\
7 & $55 /$ Kadın & AC+PTx & Var & NPM-1 & $3+7$ & $3+7$ & Ölüm \\
8 & $53 /$ Kadın & AC+PTx & Var & del(7) & Ölüm \\
10 & $59 /$ Kadın & AC & Yok & - & $3+7$ & Ölüm \\
\hline 51/Kadın & AC+PTx & Var & NPM-1 & $3+7$ & Var & Sağ \\
\hline
\end{tabular}

RT: Radyoterapi; AHKHN: Allojenik Hematopoietik Kök Hücre Nakli; AC+Ptx: Antrasiklin+ siklofosfamid ve paklitaksel; 3+7: idarubisin + sitarabin; FLAG: Fludarabin, Sitarabin ve G-CSF. 
Sekiz (\%80) hasta kemoradyoterapi alırken, 2 hasta sadece kemoterapi almıştı. Hastaların dosyalarından uygulanan toplam radyoterapi dozuna dair bilgiye ulaşılamadı. Kemoterapi olarak 7 (\%70) hastaya antrasiklin, siklofosfamid kombinasyonu ve haftalık paklitaksel uygulanmıştı. Meme kanseri tanısı ile akut lösemi tanısı arasında geçen süre median 52 ay (7-110) idi.

Tüm hastalar hematoloji polikliniğine sitopeni nedeniyle yönlendirilmişti. On (\%100) hastada anemi, 7 (\%70) hastada trombositopeni ve 6 (\%60) hastada nötropeni mevcuttu. Hastaların performans durumu Eastern Cooperative Oncology Group'a (ECOG) göre değerlendirildi.Tanı esnasında 7 hastanın performans durumu ECOG 1, 1 hasta ECOG 2, 2 hasta ise ECOG 3 idi. Genetik incelemede 2 hastada NPM 1 mutasyonu, 1 hastada ise FLT-3 mutasyonu saptandı. Meme kanseri tedavisinin tamamlanması ile akut lösemi tanısı arasında geçen süre median 17 ay (1-28) idi.

İndüksiyon tedavisi olarak 7 (\%70) hasta idarubisin ve sitarabin alırken, 1 hasta azasitidin aldı. Lösemi tanısı aldığında performansı ECOG 3 olan 2 hasta indüksiyon kemoterapisi başlanmadan kaybedildi. Bu hastalardan birinin ek olarak ciddi kalp yetmezliği mevcuttu. Illk indüksiyon sonrası hastaların yarısında tam remisyon sağlandı. Üç hastada ikinci indüksiyon tedavisinden sonra remisyon elde edilirken, 1 hasta indüksiyon tedavilerine cevap vermedi. Dört (\%40) hastaya tam uyumlu kardeş vericiden allojenik nakil yapıldı. Hastaların hepsinde kök hücre kaynağı olarak çevre kanı kullanılmıştır. Hastaların 3'ünde miyeloablatif, 1'inde azaltılmış yoğunluklu hazırlık rejimleri kullanılmıştır. Nakil yapılan 2 hasta, nakil sonrası ilk iki ayda enfeksiyon nedeniyle kaybedildi.

Sekiz (\%80) hasta hayatını kaybetti. En sık ölüm nedeni hastalık nüksü idi. İki hasta ise halen remisyonda takip edilmektedir. Akut lösemiden sonra ortanca takip süresi 14 ay (0.9-86 ay) idi.

\section{TARTIŞMA ve SONUÇ}

Tüm AML ve miyelodisplastik sendrom (MDS) vakalarının yaklaşık \%10-20'si tedaviyle ilişkili miyeloid neoplazmlardır (14). Bu çalışmada invaziv duktal meme karsinomu nedeniyle tedavi alan ve takipte AML gelişen 10 kadın hastayı sunduk. Ortalama AML tanı yaşı 54 idi. Hastaların ortalama takip süresi 14 ay (0.9-86) idi. Meme kanseri tanısı ile tedaviye bağlı lösemi gelişimi arasındaki süre yaklaşık iki yıldır (8). Hastalarımızın meme kanseri tanısı ile lösemi tanısı arasındaki süre median 52 ay idi. Meme kanseri tedavisinde yaygın olarak kullanılan alkilleyici ajanlar ve antrasiklinler (15), hastalarımızda da kullanılmıştır. Hastalarımızın tamamına meme kanseri tedavisi olarak AC protokolü (antrasiklin ve siklofosfamid) uygulanmıştı. Aynı zamanda meme kanseri tedavisinde radyoterapi de önemli bir un- surdur (15). Bu tedavi seçeneklerinin AML gelişiminde rol oynadığı düşünülmektedir. Kombinasyon ve kümülatif dozlarda kullanımının riski arttırdığı bilinmektedir (16).

İkincil löseminin yönetimi zordur ve kemoterapi mümkünse allojenik transplantasyon ile desteklenmelidir. Tedavi hastanın yaşı, performansı, komorbiditeleri ve meme kanserinin durumuna göre değerlendirilmelidir $(17,18)$. Olumsuz sitogenetik özellikler de t-AML'nin seyrini etkiler (19). Hastalarımız sitogenetik olarak incelendi. Bir hastada FLT3 pozitifliği saptandı. FLT-3 mutasyonu pozitif olan hastada üç sıra tedaviyle remisyon sağlanamadı ve dirençli hastalık nedeniyle kaybedildi. Prognoz t AML'de de novo AML'ye göre kötüdür $(20,21)$. Maalesef bizim hastalarımızda da kötü prognoz mevcuttu. On hastamızdan ikisi indüksiyon tedavisi bile alamadan hayatını kaybetti. Indüksiyon rejimi alan 8 hastanın 4'ü ilk indüksiyon tedavisine yanıt vermedi. Tedaviye bağlı AML'nin standart kemoterapi rejimlerine dirençli olabileceği ve allojenik transplantasyondan fayda sağlayabileceği literatürde bildirilmiştir $(22,23)$.

Tedavi ilişkili AML hastalarına uygulanan allojenik kök hücre nakil sonuçlarının bildirildiği bir çalışmada, allojenik transplantasyonun bu hasta grubunda önemli sağkalım faydaları olduğu gösterilmiştir. Miyeloablatif rejimlerle yapılan transplantasyonların daha iyi sonuç verdiği ve daha az nüks olduğu bildirilmiştir (24). Çalışmamızda da 4 hastaya tam uyumlu kardeş vericilerden allojenik nakil yapıldı. İki hasta remisyonda takip edilmektedir ve lösemi tanısı ardından ortalama takip süresi 56 aydır.

Sonuç olarak, tedaviye bağlı AML, meme kanserini tedavi eden klinisyenler için korkulan ve istenmeyen bir sonuçtur. Meme kanserinin erken evrede saptanması, hastaların yoğun kemoterapi ve radyoterapiye maruziyetini azaltacağından t-AML riskini de azaltacaktır. Meme kanseri tedavisi gören her hasta t-AML açısından yakından ve dikkatle izlenmelidir. Mümkünse hastalar her ziyarette periferik kan yayması ile değerlendirilmelidir. Tedaviye bağlı AML tanısı konulan hastalarda donör taraması yapılmalı ve uyumlu bir verici bulunması halinde mümkünse allojenik nakle yönlendirilmelidir.

\section{ETIK KURUL ONAYI}

Çalışma için Erciyes Üniversitesi Tıp Fakültesi Etik Kurulu'ndan onay alındı (Tarih: 22.09.2021 ve Karar no: 2021/611).

\section{ÇIKAR ÇATIŞMASI}

Yazarların çıkar çatışması bulunmamaktadır.

\section{MALI AÇIKLAMA}

Çalışma için doğrudan veya dolaylı mali destek alınmadı. Çalışma ile ilgili herhangi bir firma veya kişi ile ilgili ticari bağlantı yoktur. 


\section{YAZAR KATKISI}

Literatür taranması: ZTG, SÇ; Vakaların takip ve tedavi aşamaları: ZTG, SÇ, MK, AÜ, LK; Verilerin toplanması: ZTG; Makalenin yazımı: ZTG, LK; Onaylama: ZTG, LK.

\section{KAYNAKLAR}

1. Bray F, Ferlay J, Soerjomataram I, Siegel R, Torre LA, Jemal A. Global cancer statistics 2018: GLOBOCAN estimates of incidence and mortality worldwide for 36 cancers in 185 countries. CA Cancer J Clin 2018;68(6):394-424.

2. Yersal O, Barutca S. Biological subtypes of breast cancer: prognostic and therapeutic implications. World J Clin Oncol 2014;5(3):412-24.

3. de Santis C, Siegel R, Bandi P, Jemal A. Breast cancer statistics, 2011. CA Cancer J Clin 2011;61(6):408-18.

4. Burt LM, Ying J, Poppe MM, Suneja G, Gaffney DK. Risk of secondary malignancies after radiation therapy for breast cancer: comprehensive results. Breast 2017;35:122-9.

5. Lin CY, Chen SH, Huang CC, Weng SF, Lee ST, Guo HR, et al. Risk of secondary cancers in women with breast cancer and the influence of radiotherapy: a national cohort study in Taiwan. Medicine (Baltimore) 2016;(95):(49):e5556.

6. Briasoulis E, Tzouvara E, Tsiara S, Vartholomatos G, Tsekeris P, Bourantas K. Biphenotypic acute leukemia following intensive adjuvant chemotherapy for breast cancer: case report and review of the literature. Breast J 2003;9(3):241-5.

7. Arber DA, Orazi A, Hasserjian R, Thiele J, Borowitz MJ, Le Beau MM, et al. The 2016 revision to the World Health Organization classification of myeloid neoplasms and acute leukemia. Blood 2016;127(20):2391-405.

8. Larson RA, Le Beau MM. Prognosis and therapy when acute promyelocytic leukemia and other "good risk" acute myeloid leukemias occur as a therapy-related myeloid neoplasm. Mediterr J Hematol Infect Dis 2011;3(1):e2011032.

9. Azim Jr HA, de Azambuja E, Colozza M, Bines J, Piccart MJ. Longterm toxic effects of adjuvant chemotherapy in breast cancer. Ann Oncol 2011;22(9):1939-47.

10. Smith SM, Le Beau MM, Huo D, Karrison T, Sobecks RM, Anastasi J, et al. Clinical-cytogenetic associations in 306 patients with therapy-related myelodysplasia and myeloid leukemia: the University of Chicago series. Blood 2003;102(1):43-52.

11. Schoch C, Kern W, Schnittger S, Hiddemann W, Haferlach T. Karyotype is an independent prognostic parameter in therapy-related acute myeloid leukemia (t-AML): an analysis of 93 patients with t-AML in comparison to 1091 patients with de novo AML. Leukemia 2004;18(1):120-5.

12. Fisher B, Rockette $H$, Fisher ER, Wickerham DL, Redmond $C$, Brown A. Leukemia in breast cancer patients following adjuvant chemotherapy or postoperative radiation: the NSABP experience. J Clin Oncol 1985;3(12):1640-58.
13. Hershman D, Neugut Al, Jacobson JS, Wang J, Tsai WY, McBride $\mathrm{R}$, et al. Acute myeloid leukemia or myelodysplastic syndrome following use of granulocyte colony-stimulating factors during breast cancer adjuvant chemotherapy. J Natl Cancer Inst 2007;99(3):196-205.

14. Granfeldt Østgård LS, Medeiros BC, Sengeløv H, Nørgaard $M_{\text {, }}$ Andersen MK, Dufva IH, et al. Epidemiology and clinical significance of secondary and therapy-related acute myeloid leukemia: a national population-based cohort study. J Clin Oncol 2015;33(31):3641-9.

15. Waks AG, Winer EP. Breast cancer treatment: a review. JAMA 2019;321(3):288-300.

16. Valentini CG, Fianchi L, Voso MT, Caira M, Leone G, Pagano L. Incidence of acute myeloid leukemia after breast cancer. Mediterr $J$ Hematol Infect Dis 2011;3(1): e2011069.

17. Pulsoni A, Pagano L. Treatment of secondary acute myeloid leukemia. J Clin Oncol 2005;23(4):926-7.

18. Godley LA, Larson RA. Therapy-related myeloid leukemia. Semin Oncol 2008;35(4):418-29.

19. Sasaki K, Jabbour E, Cortes J, Kadia T, Garcia Manero G, Borthakur $\mathrm{G}$, et al. Outcome of patients with therapy-related acute myeloid leukemia with or without a history of myelodysplasia. Clin Lymphoma Myeloma Leuk 2016;16(11):616-24.

20. Morton LM, Dores GM, Schonfeld SJ, Linet MS, Sigel BS, Lam CJK, et al. Association of chemotherapy for solid tumors with development of therapy-related myelodysplastic syndrome or acute myeloid leukemia in the modern era. JAMA Oncol 2019;5(3):31825.

21. Zeidan A, Al Ali N, Barnard J, Padron E, Lancet J, Sekeres M, et al. Comparison of clinical outcomes and prognostic utility of risk stratification tools in patients with therapy-related vs de novo myelodysplastic syndromes: a report on behalf of the MDS Clinical Research Consortium. Leukemia 2017;31(6):1391-7.

22. Tang FF, Huang $\mathrm{XJ}$, Zhang $\mathrm{XH}$, Chen $\mathrm{H}$, Chen $\mathrm{YH}$, Han $\mathrm{W}$, et al. Allogeneic hematopoietic cell transplantation for adult patients with treatment-related acute myeloid leukemia during first remission: comparable to de novo acute myeloid leukemia. Leuk Res 2016;47:8-15.

23. Finke J, Schmoor C, Bertz H, Marks R, Wäsch R, Zeiser R, et al. Long-term follow-up of therapy-related myelodysplasia and AML patients treated with allogeneic hematopoietic cell transplantation. 2016;51(6):771-7.

24. Lee CJ, Labopin M, Beelen D, Finke J, Blaise D, Ganser A, et al. Comparative outcomes of myeloablative and reduced-intensity conditioning allogeneic hematopoietic cell transplantation for therapy-related acute myeloid leukemia with prior solid tumor: a report from the acute leukemia working party of the European society for blood and bone marrow transplantation. Am J Hematol 2019;94(4):431-8. 